Akka Jyothy • Kothapalli Sesha Durga Kumar

Guruju Naga Mallikarjuna Rao • Vundunti Babu Rao

Bhavanam Uma Devi • Maddireddi Sujatha

Penaguluru Pardhanandana Reddy

\title{
Parental age and the origin of extra chromosome 21 in Down syndrome
}

Received: December 21, 2000 / Accepted: March 5, 2001

\begin{abstract}
We present a report of the parental ages $(n=$ $865)$ and parental origin of meiotic nondisjunction $(n=$ 236) that are likely to show a predisposition in the etiology of Down syndrome (DS). Chromosomal analysis, performed over a 20-year period, on 1001 Down syndrome subjects, revealed pure trisomy 21 karyotype in 880 subjects (87.92\%), mosaic trisomy karyotype in 77 (7.69\%), and translocation karyotype in $44(4.39 \%)$. The mean maternal age was found to be 30.34 years, and mean paternal age was 31.04 years. Nondisjunctional error was $79.24 \%$ maternal and $20.76 \%$ paternal. The findings of the study revealed the significant contribution of advanced parental age and increased maternal meiotic nondisjunctional error to the origin of trisomy 21 Down syndrome.
\end{abstract}

Key words Down syndrome - Meiotic nondisjunction · Parental age $\cdot$ Polymorphism $\cdot$ Trisomy 21

\section{Introduction}

Ever since the discovery of the extra 21 chromosome was made, various workers have attempted to explore the cause of nondisjunction of chromosome 21. Important factors in the conception of trisomies are delayed fertilization, advanced maternal age, and increased satellite associations (German 1968; Hansson 1979; Fox and Sindwani 1985). Other factors, such as physical, biological, and chemical mutagens, have also been found to cause nondisjunction (Ghalib and Isaac 1991). The present study was performed to ascertain the role of parental ages in the occurrence of

A. Jyothy $(\bowtie) \cdot$ K.S.D. Kumar · G.N. Mallikarjuna Rao

B. Uma Devi $\cdot$ M. Sujatha $\cdot$ P.P. Reddy

Institute of Genetics and Hospital for Genetic Diseases, Osmania

University, Begumpet, Hyderabad-500 016, India

Tel. +91-040-3313681

e-mail: ksdkumar@rediffmail.com

V. Babu Rao

Institute of Immunohaematology, Mumbai, India trisomy 21 Down syndrome (DS) and to detect the origin of the extra chromosome 21 by comparing the chromosome 21 polymorphisms of the parents and their DS children.

\section{Subjects and methods}

We investigated 1001 Down syndrome subjects and their parents who were referred for cytogenetic confirmation to the Institute of Genetics and Hospital for Genetic Diseases, over a period of 20 years (January 1979 to January 1999). These subjects were referred from various districts of the state of Andhra Pradesh, South India. Complete clinical assessment of the subjects, and information pertaining to age, region, religion, habits, health status, birth order, pedigree, medical histories, parental age at the time of conception, and the reproductive history of the parents were recorded in special case records. Informed consent was obtained from the parents before inclusion in the study.

Chromosomal analysis was carried out on DS subjects and their parents, using peripheral blood lymphocyte culture, modified according to the method of Moorhead et al. (1960). A minimum of $20 \mathrm{G}$-banded metaphases were analyzed per individual, according to the method of Seabright (1971). In cases of mosaicism, 50 or more metaphases were scored. Polymorphism exhibited by chromosome 21 was recorded after thorough screening of the banded chromosomes of the DS child and the parents. Based on the size and structure of the chromosome 21, its satellites and stalks, the origin of the extra chromosome 21 was decided visually and was confirmed after microphotography.

Statistical analysis was carried out using Student's $t$-test.

\section{Results and discussion}

Chromosomal investigations were performed in 1001 Down syndrome (DS) subjects; trisomy 21 DS was shown in 880 $(87.92 \%)$ subjects, mosaic DS in 77 (7.69\%), and transloca- 
Table 1. Distribution of parental ages in Down syndrome subjects $(n=865)$

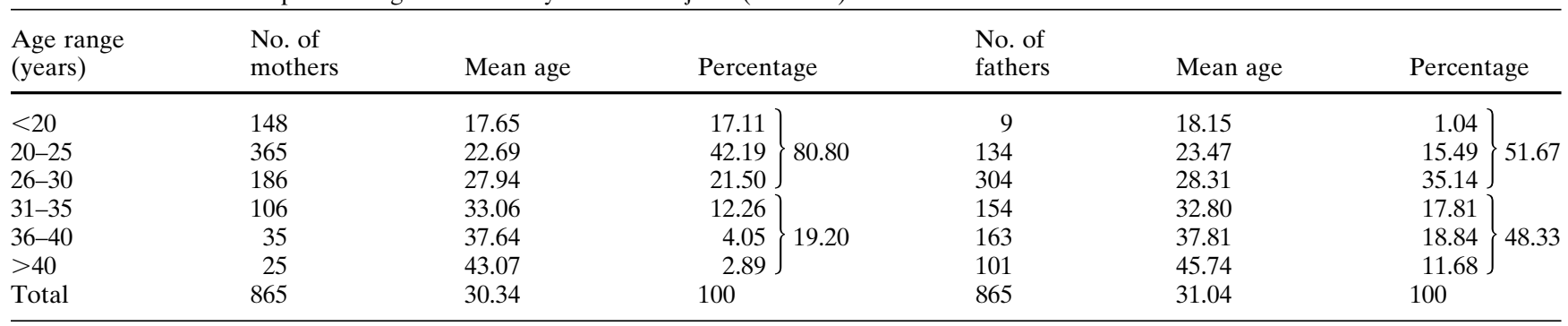

Table 2. Maternal age and Down syndrome with respect to karyotype

\begin{tabular}{|c|c|c|c|c|c|c|c|c|c|c|c|c|}
\hline \multirow{2}{*}{$\begin{array}{l}\text { Maternal } \\
\text { age } \\
\text { (years) }\end{array}$} & \multicolumn{3}{|c|}{ Control } & \multicolumn{3}{|c|}{ Trisomy 21} & \multicolumn{3}{|c|}{ Translocation } & \multicolumn{3}{|c|}{ Mosaic } \\
\hline & \multirow{2}{*}{$\frac{\text { No. }}{426}$} & \multicolumn{2}{|c|}{ Percentage } & \multirow{2}{*}{$\frac{\text { No. }}{128}$} & \multicolumn{2}{|c|}{ Percentage } & \multirow{2}{*}{$\frac{\text { No. }}{15}$} & \multicolumn{2}{|c|}{ Percentage } & \multirow{2}{*}{$\frac{\text { No. }}{5}$} & \multicolumn{2}{|c|}{ Percentage } \\
\hline$<20$ & & 42.6 & & & 16.78 & & & 38.47 & & & 7.94 & \\
\hline $20-25$ & 358 & 35.8 & 96.6 & 320 & 41.94 & 80.6 & 14 & 35.89 & 89.74 & 31 & 49.2 & 77.77 \\
\hline $26-30$ & 182 & 18.2 & & 167 & 21.88 & & 6 & 15.38 & & 13 & 20.63 & \\
\hline $31-35$ & 26 & 2.6 & & 97 & 12.72 & & 3 & 7.69 & & 6 & 9.52 & \\
\hline $36-40$ & 4 & 0.4 & 3.4 & 29 & 3.8 & 19.4 & 1 & 2.57 & 10.26 & 5 & 7.94 & 22.23 \\
\hline$>40$ & 4 & 0.4 & & 22 & 2.88 & & - & - & & 3 & 4.77 & \\
\hline Total & 1000 & 100 & & 763 & 100 & & 39 & 100 & & 63 & 100 & \\
\hline
\end{tabular}

tion DS in $44(4.39 \%)$ subjects. The sex ratio of male-tofemale DS subjects was 1.41:1.

Data pertaining to the parental ages of DS subjects at the time of conception was recorded for 865 subjects (Table 1). The mean maternal age was 30.34 years (age range, 15-46 years) and the mean paternal age was 31.04 years (age range, $18-60$ years); $80.80 \%$ of DS subjects were born to mothers of age less than 30 years and $19.2 \%$ were born to mothers aged more than 30 years. For the fathers, the percentages were 51.67 (less than 30 years) and 48.33 (more than 30 years), respectively.

In Western studies, the mean maternal age at conception of DS children was found to be 34.4 years, as compared with 28.2 years in the general population (de Grouchy and Turleau 1983). In our study, the mean maternal age was 30.34 years for DS children and 22.1 years in the general population. The mean maternal age in the present study is lower than that reported in the Western literature. This difference could be due to the fact that in South India, marriages are mostly performed at an earlier age, of 20-25 years, or even at a lower age.

Table 2 shows the distribution of maternal age in DS subjects with respect to karyotype, and controls. In subjects with pure trisomy 21 , the percentage of DS children born to mothers aged less than 30 years of age was $80.6 \%$, whereas in mosaic DS subjects, it was $77.77 \%$. We observed an increased percentage of translocation DS children $(89.74 \%)$ born to mothers less than 30 years of age. In mothers aged more than 30 years, an increased percentage $(22.23 \%)$ of mosaic DS children was observed, followed by pure trisomy $21(19.4 \%)$ and translocation DS (10.26\%). In control subjects, the percentage of normal children born to mothers aged less than 30 years was $96.6 \%$, with only $3.4 \%$ in mothers more than 30 years of age. In the present study, $0.8 \%$ of mothers in the control population were more than 35 years of age, whereas $6.68 \%$ of DS mothers were aged more than 35 years. This directly indicates that there is a relationship between maternal age effect and DS.

Paternal age has also been implicated in the etiology of trisomy 21 Down syndrome, but the evidence is contradictory. Table 3 shows the distribution of paternal age in DS subjects with respect to karyotype. A significantly increased incidence of Down syndrome was reported in the children of Danish men over 55 years of age by Stene et al. (1977). Similar findings were reported by Matsunaga et al. (1978) for Japanese men and by Erickson and Bjerkedal (1981) in the Norwegian population. However, studies by Roth et al. (1983) and Roecker and Huether (1983) failed to find a possible link to increasing paternal age and the incidence of DS. In the present study, the percentage of fathers aged more than 40 years was greater in the trisomy 21 DS group $(12.72 \%)$ compared with controls, translocation DS, and mosaic DS subjects, indicating a possible role of paternal age in the etiology of trisomy 21 DS.

Data on parental age in relation to the contribution of chromosome 21 are presented in Table 4 . The mean maternal age of mothers contributing the extra chromosome 21 was estimated as $26.66 \pm 5.95$ years, and mean paternal age was estimated as $32.46 \pm 6.61$ years.

Table 5 shows the parental origin of meiotic nondisjunction of chromosome 21. Detection of the parental origin of chromosome 21 was possible in only 236 subjects. Nondisjunctional error was $79.24 \%(n=187)$ maternal and $20.76 \%$ $(n=49)$ paternal. Among the 187 mothers, the first meiotic nondisjunction was observed in 149 (63.14\%) subjects and the second meiotic nondisjunction was observed in 38 $(16.10 \%)$ subjects. In fathers, the first and second meiotic 
Table 3. Paternal age and Down syndrome with respect to karyotype

\begin{tabular}{|c|c|c|c|c|c|c|c|c|c|c|c|c|}
\hline \multirow{2}{*}{$\begin{array}{l}\text { Paternal age } \\
\text { (years) }\end{array}$} & \multicolumn{3}{|c|}{ Control } & \multicolumn{3}{|c|}{ Trisomy 21} & \multicolumn{3}{|c|}{ Translocation } & \multicolumn{3}{|c|}{ Mosaic } \\
\hline & \multirow{2}{*}{$\frac{\text { No. }}{18}$} & \multicolumn{2}{|c|}{ Percentage } & \multirow{2}{*}{ No. } & \multicolumn{2}{|c|}{ Percentage } & \multirow{2}{*}{ No. } & \multicolumn{2}{|c|}{ Percentage } & \multirow{2}{*}{$\frac{\text { No. }}{1}$} & \multicolumn{2}{|c|}{ Percentage } \\
\hline$<20$ & & 1.8 & & & 1.05 & & & - & & & 1.59 & \\
\hline $20-25$ & 476 & 47.6 & 77.8 & 106 & $13.89\}$ & 49.28 & 10 & 25.64 & 71.79 & 18 & 28.57 & 68.25 \\
\hline $26-30$ & 284 & 28.4 & & 262 & 34.34 & & 18 & 46.15 & & 24 & 38.09 & \\
\hline $31-35$ & 146 & 14.6 & & 137 & 17.95 & & 7 & 17.95 & & 10 & 15.87 & \\
\hline $36-40$ & 72 & 7.2 & 22.2 & 153 & 20.05 & 50.72 & 3 & 7.7 & 28.21 & 7 & 11.11 & 31.75 \\
\hline$>40$ & 4 & 0.4 & & 97 & 12.72 & & 1 & 2.56 & & 3 & 4.77 & \\
\hline Total & 1000 & 100 & & 763 & 100 & & 39 & 100 & & 63 & 100 & \\
\hline
\end{tabular}

Table 4. Distribution of maternal and paternal age in relation to the origin of nondisjunction $(n=236)$

\begin{tabular}{|c|c|c|c|c|c|c|c|}
\hline $\begin{array}{l}\text { Serial } \\
\text { no. }\end{array}$ & $\begin{array}{l}\text { Age } \\
\text { (years) }\end{array}$ & $\begin{array}{l}\text { Number of } \\
\text { mothers }\end{array}$ & $\begin{array}{l}\text { Percentage } \\
(\%)\end{array}$ & Mean \pm SD & $\begin{array}{l}\text { Number of } \\
\text { fathers }\end{array}$ & $\begin{array}{l}\text { Percentage } \\
(\%)\end{array}$ & Mean $\pm \mathrm{SD}$ \\
\hline 1 & $<20$ & 21 & 11.23 & \multirow[t]{6}{*}{$26.66 \pm 5.95$} & - & - & \multirow[t]{6}{*}{$32.46 \pm 6.61$} \\
\hline 2 & $20-25$ & 73 & 39.04 & & 5 & 10.20 & \\
\hline 3 & $26-30$ & 49 & 26.21 & & 19 & 38.77 & \\
\hline 4 & $31-35$ & 29 & 15.50 & & 11 & 22.45 & \\
\hline 5 & $36-40$ & 12 & 6.42 & & 8 & 16.33 & \\
\hline 6 & $>40$ & 3 & 1.60 & & 6 & 12.25 & \\
\hline
\end{tabular}

Table 5. Parental origin of chromosome 21 at meiotic nondisjunction in relation to parental age $(n=236)$

\begin{tabular}{|c|c|c|c|c|c|c|c|c|c|}
\hline $\begin{array}{l}\text { Serial } \\
\text { no. }\end{array}$ & $\begin{array}{l}\text { Type of } \\
\text { origin }\end{array}$ & $\begin{array}{l}\text { Number of } \\
\text { parents }\end{array}$ & $\begin{array}{l}\text { Percent } \\
(\%)\end{array}$ & $\begin{array}{l}\text { M I } \\
\text { no. }\end{array}$ & $\begin{array}{l}\text { Percent } \\
(\%)\end{array}$ & $\begin{array}{l}\text { Mean age } \\
(\text { mean } \pm \text { SD) }\end{array}$ & $\begin{array}{l}\text { M II } \\
\text { no. }\end{array}$ & $\begin{array}{l}\text { Percent } \\
(\%)\end{array}$ & $\begin{array}{l}\text { Mean age } \\
(\text { mean } \pm \mathrm{SD})\end{array}$ \\
\hline 1 & Maternal & 187 & 79.24 & 149 & 63.14 & $27.02 \pm 6.0$ & 38 & 16.10 & $25.26 \pm 5.63$ \\
\hline 2 & Paternal & 49 & 20.76 & 35 & 14.83 & $31.65 \pm 6.09$ & 14 & 5.93 & $34.50 \pm 7.63$ \\
\hline
\end{tabular}

M I, Meiotic stage I; M II, meiotic stage II

Table 6. Pooled data on the frequency of meiotic nondisjunction of chromosome 21 in parents of Down syndrome subjects

\begin{tabular}{|c|c|c|c|c|c|}
\hline \multirow[b]{2}{*}{ Authors and year } & \multirow{2}{*}{$\begin{array}{l}\text { Total number of } \\
\text { parents screened }\end{array}$} & \multicolumn{2}{|c|}{$\begin{array}{l}\text { Maternal meiotic } \\
\text { division }\end{array}$} & \multicolumn{2}{|c|}{$\begin{array}{l}\text { Paternal meiotic } \\
\text { division }\end{array}$} \\
\hline & & $1 \mathrm{st}$ & 2nd & $1 \mathrm{st}$ & 2nd \\
\hline Magenis et al. (1977) & 128 & $\begin{array}{l}76 \\
(59.38)\end{array}$ & $\begin{array}{l}21 \\
(16.41)\end{array}$ & $\begin{array}{l}16 \\
(12.50)\end{array}$ & $\begin{array}{l}15 \\
(11.72)\end{array}$ \\
\hline Mattei et al. (1979) & 42 & $\begin{array}{l}29 \\
(69.05)\end{array}$ & $\begin{array}{l}5 \\
(11.90)\end{array}$ & $(9.52)$ & $\begin{array}{l}4 \\
(9.52)\end{array}$ \\
\hline Buraczynska et al. (1989) & 22 & $\begin{array}{l}17 \\
(77.27)\end{array}$ & $\begin{array}{l}3 \\
(13.63)\end{array}$ & $\begin{array}{l}1 \\
(4.55)\end{array}$ & $\begin{array}{l}1 \\
(4.55)\end{array}$ \\
\hline Present study & 236 & $\begin{array}{l}149 \\
(63.14)\end{array}$ & $\begin{array}{l}38 \\
(16.10)\end{array}$ & (14.83) & $\begin{array}{l}14 \\
(5.93)\end{array}$ \\
\hline Total & 428 & $\begin{array}{l}271 \\
(63.32)\end{array}$ & $\begin{array}{l}67 \\
(15.65)\end{array}$ & $\begin{array}{l}56 \\
(13.08)\end{array}$ & $\begin{array}{l}34 \\
(7.95)\end{array}$ \\
\hline
\end{tabular}

nondisjunctions were observed in 35 (14.83\%) subjects and $14(5.93 \%)$ subjects, respectively.

Statistical analysis of maternal age, according to meiotic I and meiotic II error, showed mean values of $27.02 \pm 6.0$ and $25.26 \pm 5.63$ years, respectively (Table 5). The mean maternal age for meiotic I error was comparatively higher than that for meiotic II error.

Similarly, statistical analysis of paternal age showed the mean values to be $31.65 \pm 6.09$ years for meiotic I error and $34.5 \pm 7.63$ years for meiotic II error. The mean paternal age for meiotic I error was lower than that for the meiotic II error. Paternal age could be a factor in the etiology of DS, if the age is advanced.

Maternal and paternal ages in relation to the contribution of chromosome 21 in mosaic DS subjects were $27.4 \pm$ 5.31 years and $32.12 \pm 5.64$ years, respectively. There was no significant age difference between the parents of mosaic DS subjects and trisomy 21 DS subjects $(P>0.05)$.

In the present study, the frequency of meiotic I abnormality was predominant over meiotic II abnormality for 
both sexes. Pooled data from the present study and studies reported earlier (Table 6), by Magenis et al. (1977), Mattei et al. (1979), and Buraczynska et al. (1989), also revealed that maternal meiotic I nondisjunction was predominantly responsible for the trisomic condition in Down syndrome children. Similar findings were also reported recently by Ballesta et al. (1999).

The findings of the present study, carried out in a population of large sample size, indicated the significant effect of advanced parental ages and maternal meiotic errors in the occurrence of trisomy 21 Down syndrome. The study of the origin of the extra chromosome 21 helped us to offer appropriate genetic counselling and prenatal diagnosis to the couples for their future pregnancies.

Acknowledgments The authors are grateful to Professor O.S. Reddi, Former Director, Institute of Genetics, and the Late Dr. G.S. Issac, Head, Division of Human Cytogenetics, for providing the laboratory facilities to carry out this work. We acknowledge the technical assistance of Mr. M.P.R. Chary, Mr. C.S. Rao, Mr. K.S. Rao, and Mr. G. Vigneshwar. We are thankful to the University Grants Commission, New Delhi, and the Government of Andhra Pradesh for their financial support.

\section{References}

Ballesta F, Queralt R, Gomez D, Solsona E, Guitart M, Ezquerra M, Moreno J, Oliva R (1999) Parental origin and meiotic stage of non-disjunction in 139 cases of trisomy 21 . Ann Genet 42:11-15
Buraczynska M, Stewart GD, Sherman S, Freeman V, Grantham M, Uchida I, Hassold T, Kurnit D (1989) Molecular and cytogenetic studies of non-disjunction. Alan R. Liss, New York, pp 101-113

de Grouchy J, Turleau C (1983) Clinical atlas of human chromosomes. Wiley, New York, pp 58-65; 84-86; 211-216; 319

Erickson JD, Bjerkedal T (1981) Down syndrome associated with fathers age in Norway. J Med Genet 18:22-28

Fox D, Sindwani V (1985) Satellite association. Karyogram 11:3

German J (1968) Mongolism, delayed fertilization and human sexual behaviour. Nature 217:84-90

Ghalib MA, Isaac GS (1991) Paternal consanguinity in Down syndrome. Ann Natl Acad Med Sci (India) 27:43-46

Hansson A (1979) Satellite association in human metaphases. A comparative study of normal individuals, patients with Down syndrome and their parents. Hereditas 90:59-83

Magenis RE, Overton KM, Chamberlin J, Brady T, Lovrien E (1977) Paternal origin of the extra chromosome in Down's syndrome. Hum Genet 37:7-16

Matsunaga E, Tonomura A, Oishi H, Kikuchi Y (1978) Reexamination of paternal age effect in Down Syndrome. Hum Genet 40:299-306

Mattei JF, Mattei MG, Ayme S, Giraud F (1979) Origin of the extra chromosome in trisomy 21. Hum Genet 46:107-110

Moorhead PS, Nowell P, Mellman J, Hungerford DA (1960) Chromosome preparations of leukocytes cultured from human peripheral blood. Exp Cell Res 20:613-616

Roecker G, Huether C (1983) An analysis for paternal age effect in Ohio's Down syndrome births. Am J Hum Genet 35:1297-1306

Roth MP, Feingold J, Baumgarten A, Bigel A, Stoll C (1983) Reexamination of paternal age effect in Down's syndrome. Hum Genet 63:149-152

Seabright MA (1971) Rapid banding technique for human chromosomes. Lancet II: 971-972

Stene T, Fischer G, Stene E, Mikkelson M, Peterson E (1977) Paternal age effect in Down's syndrome. Ann Hum Genet 40:299-306 